\title{
HOW RESPONSIVE ARE PRIVATE TRANSFERS TO INCOME? EVIDENCE FROM A LAISSEZ-FAIRE ECONOMY
}

\author{
Donald Cox* Bruce E. Hansen** and Emmanuel Jimenez***
}

November 1999

JEL Classification: O15, O16, J14, I30, H55

Keywords: Altruism, Exchange, Private Transfers, Crowding Out

*Department of Economics, Boston College.

**University of Wisconsin, Madison.

***The World Bank.

\footnotetext{
This work was supported by RPO 676-24 of the World Bank's Research Committee Support Budget and the National Institute on Aging. We would like to thank Richard Arnott and Andrew Foster for valuable comments on a previous draft. We also wish to thank seminar participants at the RAND Corporation, University of Southern California and the 1997 Northeast Universities Development Consortium for useful comments on earlier drafts. Homi Kharas provided us with the FIES data set. A GAUSS program which replicates the empirical work can be obtained at www.ssc.wisc.edu/ bhansen. Hansen thanks the National Science Foundation and the Sloan Foundation for research support. The views expressed here are the authors' own and should not be attributed to the Government of the Philippines.
} 


\begin{abstract}
In recent years there has been rapidly growing interest in the responsiveness of private transfers to household income, or "transfer derivatives." Undoubtedly most of the interest in transfer derivatives is fueled by the problem of "crowding out": If incomes are fungible, and private transfers are highly responsive to household resources, expansion of public transfers could serve merely to supplant private ones, leaving the distribution of household consumption largely unchanged. Yet there is also an emerging consensus from empirical work that these transfer derivatives are rather small, at least for the United States, implying that crowding out might loom larger in the minds of some economists than in the data.
\end{abstract}

A possible reason for the lack of evidence for crowding out in a developed country like the United States is that the substantial public transfers that already exist could have rendered it a fait accompli, leaving the remaining small samples uninformative about crowding out. In this paper, we focus on the Philippines, a country with extremely limited public income redistribution. We also pay attention to the possibility that theoretical models of private transfers, including models of altruism and household risk-sharing, can imply a non-linear relationship between inflows of private transfers and household resources, taking the form of a spline. We estimate this model by non-linear least squares, treating the threshold (knot point) as an unknown parameter, using recently developed econometric techniques. This allows for a more exact measurement of transfer derivatives than the more commonly applied monotonic approach. We find that private transfers are widespread, and that they can be highly responsive to household economic status, in a way that is consistent with either altruistic preferences, effective household risk-sharing, or both. A strong transfer derivative occurs, however, only for the very poorest households, where decreases in their resources prompt very large increases in private transfers.

Our findings have significant policy implications, because they imply that attempts to improve the status of the very poorest households could be thwarted by private responses. Some of the gains from public transfers would be shared with richer households whose burden of support for their less fortunate kin is eased. So the problems that operative private transfers create for public income redistribution, first pointed out by Becker and Barro nearly 25 years ago, do indeed matter empirically. 


\section{INTRODUCTION}

How responsive are private, inter-household income transfers to household resources? This relationship, called "transfer derivatives," is important because it has both normative and positive implications. If private transfers respond sharply to changes in household resources, government-mandated transfers could conceivably have limited distributional effect, because they might simply "crowd out" private ones. From the earliest treatment of private transfers, in the work of Becker (1974) and Barro (1974), crowding out has been raised as a theoretical possibility. In addition to policy concerns, we may be interested in the responsiveness of private transfers to household income because it may shed light on the underlying motivation for them. For example, the altruistic model of transfer behavior predicts that private transfers increase significantly with reductions in household resources. Similarly, if transfers are used to mitigate risks that households face, we would expect them to follow the same qualitative pattern, even if they are not altruistically motivated. Alternatively, if they are used as payments in a two-way exchange, they could be either positively or negatively related to household resources (Cox [1987]).

The existing evidence, however, suggests that "crowding out" is a non-issue, at least for developed countries. There are no empirical studies that indicate a dramatic response of private transfers to household resources. Most imply that a dollar reduction in the income of transfer recipients would be met with just a few cents of extra transfers, and some indicate there might even be a small reduction. Cox and Jakubson (1995), for example, estimate that a dollar increase in public welfare spending would likely be met

with no more than a 12 cent reduction in private transfers. Altonji, Hayashi and Kotlikoff (1997) find similarly tepid transfer derivatives. Despite the focus in the theoretical 
literature on the specter of crowding out, there does not seem to be much evidence for it, generating considerable tension between theory and empirics.

The United States might be the wrong place to look for crowding out, however, because its existing public spending may have already rendered it a fait accompli. We can only speculate about the exact magnitude of the reduction in private transfers caused by the early expansions of public income redistribution in the United States in the 1930's and 1960's, for example, because a consistent time-series for private transfers does not exist. However, another form of private transfer, charity, appears to have been displaced dollar-for-dollar by the public relief programs of the 1930's (Roberts [1984]). ${ }^{1}$

This reasoning suggests that we turn to other settings to examine private transfers, which are not nearly as widespread or as large a fraction of income in the United States as in developing countries. Data from countries with smaller systems of public redistribution might afford a cleaner test of the crowding out hypothesis.

There is perhaps a second reason for the paucity of evidence for crowding out. Even if economists look in the right places (i.e., countries with meager public income redistribution) they might mistakenly mis-measure the strength of transfer derivatives because of model mis-specification. For example, a variant of the Becker altruist model, augmented to include the possibility of inter-household exchange, implies that the transfer-income relationship can be highly non-linear. Other commonly used models of household transfers, such as the risk-sharing model, in which preferences are not necessarily altruistic, can also imply non-constant transfer derivatives. In our empirical

\footnotetext{
${ }^{1}$ In addition to private transfers and charity, there are several other possible private behavioral responses to social insurance: labor supply (Moffitt [1992]), savings (Feldstein [1974]), and private insurance purchases (Cutler and Gruber [1996]), for example. Cox and Jimenez (1995) argue that, while most behavioral responses redound to program recipients, private transfer distortions are more troublesome for targeting poverty alleviation because they tend to benefit high-income private donors.
} 
work, we posit that the non-linearities take the form of a spline. We estimate this model by non-linear least squares, treating the threshold as an unknown parameter, using recently developed econometric techniques (Hansen [1996], Chan and Tsay [1998]). Our empirical work indicates that failure to specify such non-linearity can cause transfer derivatives to be severely mis-measured.

The intuition for the non-linearity in income-transfer relationships comes from thinking about the strength and type of transfer motive that is likely to prevail depending on the potential recipient's income. Imagine a household facing especially dire straits and receiving outside private help. The transfers it receives might conceivably be motivated by a friend or relative's unvarnished altruism, much in the same way that the rescue of a drowning man might be motivated by concern for the victim's life and nothing else. These altruistic transfers are predicted to have especially strong transfer derivatives (Becker [1974]). But let the household's own resources expand and the altruistic motivation for transfers may evaporate. This doesn't imply that private transfers necessarily disappear, because they could still occur, only now for non-altruistic reasons, such as payments in exchange. The key point is that these other transfers need not have as dramatic transfer derivatives. The transfer derivative depends on the transfer motive, which in turn depends on household pre-transfer income.

We use the altruism motive only as an illustration. We cannot prove that transfers, even if they are highly responsive to household incomes, are necessarily altruistic. For example, perhaps households enter into mutually beneficial, self-interested co-insurance contracts, which can imply similar non-linearities in transfer derivatives. Household A might promise to provide help to B once B's resources drop below a certain 
level. Contracts like these can generate non-linearities in the transfer income relationship.

We use data for the Philippines, a country with minimal public income redistribution, and find that private transfers follow a sharp, non-linear pattern which implies substantial crowding out for lower-income households, but much weaker transfer derivatives for other households. We also find that ignoring the non-monotonicity in the transfer-income relationship generates deceptively small transfer derivatives, similar to the ones that characterize many studies of transfer behavior which ignore non-linearities. Our findings have potentially far-reaching implications for government behavior and policy, implying that government attempts to alter the distribution of economic wellbeing can sometimes be thwarted by private behavioral responses. Simple analyses that ignore these responses can make public transfer programs appear more effective than they really are.

The findings also could have implications for our understanding of human nature and underlying motivations for private transfers, but here we must tread cautiously. Our finding of strong transfer derivatives for lower-income households is consistent with, though certainly not proof of, altruistic preferences. It is obviously illogical to accept the hypothesis of altruism--or any other behavioral hypothesis for that matter, because the same empirical patterns may be generated by, for example, self-interested co-insurance contracts, or some other process. Still, we find the consistency with the predictions of the altruism model noteworthy in light of previous theoretical and empirical work. Altruistic preferences are often invoked on commonsense grounds. ${ }^{2}$ But after being taken to the

\footnotetext{
${ }^{2}$ For example, Becker and Murphy (1988) argue that "The altruism assumption is supported by the many sacrifices parents frequently make for children. Parents spend money, time, and effort on children through child care, expenditures on education and health, gifts, and bequests." (Becker and Murphy [1988, p. 3]).
} 
data the altruism model has emerged beleaguered--up until now there has been hardly a shred of evidence to support it. So it is striking that we find transfer derivatives that are consistent with altruism, though we hasten to add that altruistic preferences are not necessary for the patterns we find.

\section{NON-MONOTONIC TRANSFER-INCOME RELATIONSHIPS}

There are several explanations why the transfer-income relationship may be nonmonotonic. They include: the exchange versus altruistic motives for giving (loan repayments can be modeled within this framework), and the insurance motive for transfers.

\section{A. Altruism and Exchange}

A leading dichotomy in the literature, for example, is that of altruistic versus exchange-motivated transfers. Recent papers which allude to these alternate motives include, for example, Laitner (1997), McGarry and Schoeni (1995) and Ioannides and Kan (1993). We show that this framework, which has become somewhat standard in the literature on private transfers, can imply a non-constant transfer derivatives once we account for the possibility that the two motives may co-exist.

When transfer donors have alternating altruistic and selfish concerns, transfer receipts can exhibit a non-linear pattern in recipient income, first falling sharply and then leveling off or even rising. The pattern is determined by the motive prevailing at the margin, and the fact that altruism is more likely to be operative at the margin when recipients are in dire straits. Donors who help desperately poor relatives or bystanders who attempt to save drowning victims, act not in expectation of remuneration but solely out of altruistic concern. Their contributions have a pronounced inverse relationship with recipient resources. The introduction of a poverty alleviation program, for example, or the sudden appearance of a rescue squad, allow donors to cut back sharply on the provision of help. So when recipients are desperate, transfers are altruistically motivated 
and they fall sharply with improvements in recipient resources. The model of private transfers which predominates at this stage is the altruism model of Becker [1974]. ${ }^{3}$

But when recipients are well-off enough, transfers cease to be altruistic at the margin. The donor may still care about the recipient (and be happy to learn, for example, of the latter's recent lottery winnings) without going out of his way to make him better off. But the lack of an altruistic motive need not imply that no transfers occur. Unlike the Becker-Barro model, in which the transfer motive ceases to be operative once the limits of altruism are reached, our approach allows for non-altruistic transfers. For example, the donor might contribute money to the recipient, but with the expectation of receiving a quid pro quo. ${ }^{4}$ Unlike altruistic transfers, non-altruistic transfers need not be bear a strong, inverse relationship to recipient incomes. (Indeed, the two may be positively related, as in the case where recipients are paid their hourly wage for providing time-intensive services.) So recipient resources rise to a certain threshold where the transfer motive switches from altruism to exchange. At that point the relationship between recipient income and transfer amounts received can change dramatically. Hence the importance of the non-linear specification between the two variables.

Consider the following simple model of transfers, a variant of the one in Cox [1987]. Suppose the utility of the donor, $U_{d}$, is given by

$$
U_{d}=U\left(C_{d}, s, V\left(C_{r}, s\right)\right)
$$

where $V=$ recipient's well-being, $C_{i}, i=d, r$ denote donor and recipient consumption, and $s$ denotes "services" that the recipient might provide to the donor. ${ }^{5}$

Expression (1) embodies both altruism and exchange. The donor cares about the recipient so that $\partial U_{d} / \partial V>0$. But the recipient must be compensated with financial

\footnotetext{
3 Though the analysis below is expressed in terms of "donors" and "recipients," analyses of altruism are usually applied to family behavior, and therefore we could just as well substitute, for example, the term "parent" for donor and "child" for recipient. The donor-recipient labels are chosen merely for convenience. ${ }^{4}$ In the Filipino context, the quid pro quo might spring from a form of reciprocity called utang na loob, literally "debt inside oneself," which compels recipients to repay donors [Lopez, 1991].

5 For simplicity, and without losing anything essential, we assume that (1) is additively separable.
} 
transfers for any services he provides, because we assume that $\partial V / \partial s<0$. The partial effects of the other arguments in (1) are positive. In particular, the donor enjoys services provided by the recipient. The budget constraints for donor and recipient are $C_{d}=I_{d}-T$ and $C_{r}=I_{r}+T$, where $T$ denotes financial transfers given by the donor to the recipient and the $I_{i}$ are pre-transfer incomes.

The name "services" is a catch-all term that stands for anything that the recipient provides to the donor in exchange for financial transfers. Services might include help with home production or behaving in a way the donor prefers. Alternatively, "services" might capture financial transfers that the recipient makes to the donor at a later date. In this instance, if $T$ is a loan from donor to recipient, then $s$ denotes the discounted value of loan repayments.

We assume that there are no market substitutes for transfers or services so that donor and recipient are engaged in a bilateral monopoly problem when they make exchanges. One way to resolve the problem is to assume that the donor dominates the bargaining arrangement. ${ }^{6}$ This assumption implies that exchange-motivated transfers provide exact compensation for services. The "donor-dominates" assumption has the virtue of nesting the traditional altruism formulation of Becker [1974] and Barro [1974] in a model that contains both altruistic and exchange motives for transfers.

When is a transfer altruistic and when is it exchange-related? The recipients' utility from severing relations with the donor is $V_{0}=V\left(I_{r}, 0\right)$--the recipient receives no transfers and provides no services. The dominant donor faces the participation constraint that $V=V_{0}$. If the constraint is binding, the transfer is exchange-related--transfers provide exact compensation for services. Otherwise, transfers are altruistic because they increase the well-being of the recipient. Suppose transfers are altruistically motivated.

\footnotetext{
${ }^{6}$ One alternative is Nash bargaining (e.g., McElroy, 1990) which has the attractive feature of conferring to the recipient some gains from exchange. But Nash bargaining does not include the Becker-Barro version of altruism as a special case. Since it is this form of altruism which is of primary interest to us, we opt for the assumption that the donor is dominant.
} 
In this case, $\partial T / \partial I_{r}<0$. Recipients with higher pre-transfer income require smaller transfers to attain the level of consumption that is optimal from the donor's point of view. The effect of $I_{r}$ on $T$ can be large. For example, with Cobb-Douglas preferences and equal weighting of donor and recipient utility $(\partial U / \partial V=1)$, the value of $\partial T / \partial I_{r}$ is minus one-half.

If transfers are exchange motivated, the relationship between $T$ and $I_{r}$ is different. Think of transfers as the product of an implicit price of services, $p$, and $s$. It is easy to show that $\partial s / \partial I_{r}<0$ and $\partial p / \partial I_{r}>0$ (Cox [1987]). So transfers can rise or fall with $I_{r}$ depending on whether the price effect dominates the quantity effect. It can be shown that, if transfers both rise and fall with $I_{r}$, they will first rise and then fall, generating an inverted-U-shaped relationship between transfers and recipient income. ${ }^{7}$

The participation constraint makes it clear why altruism prevails when recipient income is low, because in this case the constraint does not bind. Donors with an indigent relative make transfers strictly to raise his well-being. Once recipients become well of enough, exchange becomes the operative motive at the margin.

With these results in mind, we describe the relationship between recipient income and transfers, which is depicted in Figure 1. Start with a very low value for recipient income--somewhere between 0 and $K$. The recipient is poor, so the transfer is altruistic, and transfers fall with recipient income. But once the threshold $K$ is reached, transfers become exchange-motivated, where they have an inverted-U-shaped relation to recipient income. Finally, once the recipient's income becomes large enough $\left(I_{r}^{\prime \prime}\right)$ he becomes independent of the donor, and transfers cease altogether.

The simple model is informative for empirical work in two ways. First, it suggests that specifications of transfer functions should be non-linear in recipient income. Second, the model can address the "crowding-out" of private transfers by public ones. Suppose a public income transfer scheme raises every low-income household's

\footnotetext{
${ }^{7}$ See, for example, Cox (1987).
} 
income to $K$. Then altruistically motivated transfers will disappear, leaving only exchange-related ones. Further increases in public transfers can actually "crowd in" private transfers if they occur along the segment $K--I_{r}$. Finally, if public transfers expand enough to give everyone a minimum income of $I_{r}^{\prime \prime}$, private transfers may disappear altogether.

\section{B. Household Risk-Sharing}

While one facet of the literature on private transfers emphasizes the role of altruism and other motivations for private transfers in the family, another, related approach analyzes private transfers one of many strategies households use to pool risk. As Becker (1974) noted in his seminal work on social interactions, operative, altruistic transfers can imply effective risk-sharing between donor and recipient. But altruism is not necessary for such co-insurance to occur, and there have been many recent papers which have analyzed the connection between private interhousehold transfers and the sharing of risks in a non-altruistic environment. We demonstrate below that these models, like the altruism-exchange framework, can imply non-constant transfer derivatives.

Townsend (1994) analyzes and tests risk-sharing behavior for a sample of Indian farm households. To cope with stochastic shocks which affect its resources, a household participates in a risk-sharing group, an aggregation of households in which resources are pooled and shared, leaving it vulnerable only to shocks which impinge on the group at large.

Analytically, the problem of risk-sharing is nearly identical to that which arises in a family characterized by altruism, except that decisions are made by a "social planner" rather than by the family head (see, e.g., Mace [1991). In addition, the risk-sharing literature has tended to emphasize all forms of coping with risk, including, in addition to inter-household transfers, other forms of household redistribution, financial intermediation, and the like. And while the empirical work has tended to focus on the 
"bottom line" of consumption outcomes, rather than the risk-sharing methods themselves, the implications for transfers are similar to those predicted by the altruism model. If private, inter-household transfers are used for dealing with risks associated with shortfalls in household resources, then transfers receipts and recipient resources should be inversely related. In addition, under full risk-sharing we would expect that transfers would be more responsive to income at low levels of recipient income, since a disproportionate number of these households would have been likely to experience negative income shocks to be remedied by insurance payments. At very low incomes, the effects of these shocks might be profound as households struggle to survive, necessitating greater "insurance" payments. For those who are able to access precautionary savings or formal insurance or credit channels, negative income shocks are less likely to trigger dramatic private transfer responses. So with household risk-sharing, as with altruistically motivated transfers, there are likely to be non-linearities in transfer derivatives. ${ }^{8}$ Moreover, such a relationship would be discontinuous depending upon access to formal insurance or capital markets.

\section{EVIDENCE ON TRANSFER DERIVATIVES}

Are private transfers responsive to recipient incomes? The existing literature analyzing private transfers in the United States indicates that the answer is no. The earliest empirical studies of the connection between private transfers and income concerned bequests to children, and the predominant pattern was found to be equal sharing among children (e.g., Menchik [1980]). Later studies, such as Wilhelm (1996), were better able to control for the characteristics of children but produced essentially the same result, indicating that private transfers, at least in the form of bequests, were

\footnotetext{
${ }^{8}$ Other, more subtle non-linearities may arise from problems of commitment and implementability of risksharing (e.g., Coate and Ravallion [1993]). Co-insurance schemes for protecting against extreme disasters may not be sustainable between two self-interested parties who always have the option of defecting from their informal insurance arrangements. This "implementability constraint" serves to limit transfer payments to households who have experienced extreme shocks. Considerations like these introduce non-linearities that differ from those in figure 1. Transfers are only responsive to household income if such income is high enough that the implementability constraint does not bind. Once the shock becomes so severe that this constraint binds, transfers no longer expand with further reductions in income (see Coate and Ravallion, pp. 10-11).
} 
remarkably insensitive to the incomes of potential recipients. Inter-vivos transfers might be thought to be more compensatory because they are more likely to be deliberate. But existing studies point either to positive income effects (e.g., Cox [1987]), or negative effects that are quite small in magnitude (e.g., McGarry and Schoeni [1995]). ${ }^{9}$

Transfer derivatives have been used to test various motives for private transfers (e.g., Cox [1987], Altonji, Hayashi and Kotlikoff [1997]). Altruism places a restriction on these derivatives: A dollar increase in recipient income, accompanied by a dollar decline in donor income, should prompt an exact dollar reduction in private transfers. This restriction was tested and rejected by Cox and Rank [1992] and Altonji, Hayashi and Kotlikoff [1997]. The former find positive recipient income effects for transfers and the latter find negative income effects, but in each case altruism's restrictions are rejected because the estimated transfer derivatives were quite small.

Perhaps one reason for the small income effects on transfers in the United States is that public income transfer programs have already crowded out the transfers most likely to be responsive to income. The evidence for developing countries is less clear cut. Some studies find an inverse relationship between recipient income and transfer amounts (e.g., Kaufmann and Lindauer [1986; El Salvador], Kaufmann [1982; the Philippines] and Ravallion and Dearden [1988; rural households in Java]. But other studies find a positive relationship (e.g., Lucas and Stark [1985; Botswana] Ravallion and Dearden [1988; urban households in Java] and Cox and Jimenez [1997; urban households in Peru]. A problem with each of these studies, however, is that none contains a specification for recipient income that is flexible enough to capture the complete transfer pattern depicted in Figure 1.10

\footnotetext{
${ }^{9}$ For a review of studies which address the separate issue of the overall size of private transfers in the United States, see Gale and Scholtz (1994).

${ }^{10}$ The only study which approaches the subject of non-linearities, and finds substantial income effects, is that of Kaufmann [1982], which we discuss in more detail below. In addition, a recent paper by Schoeni (1997) emphasizes non-constant transfer derivatives and finds income effects that are qualitatively consistent with Figure 1. But his estimated transfer derivatives, like those found in the rest of the United States studies, are minuscule.
} 
In sum, lack of flexibility in functional form and the existence of a large welfare state in the United States may have made it difficult to detect evidence for substantial transfer derivatives. Since our work is for a country with little in the way of public safety nets, we should be able to better detect the full range of behavior depicted in Figure 1. Before proceeding to the empirical work, we place the public safety nets of the Philippines in perspective.

\section{SOCIAL INSURANCE IN THE PHILIPPINES}

How does the Philippines compare to other countries in terms in terms of allocation of GNP to social welfare spending? The table below indicates rankings for an assortment of countries for welfare and other payments ${ }^{11}$. The fraction of GNP devoted to social welfare spending in the Philippines is several orders of magnitude smaller that of developed countries such as the United States and the United Kingdom, and it is dwarfed by those of welfare states like Sweden and the Netherlands. Even among other developing countries similarly classified as "middle income," such as Morocco, Korea and Thailand, the share of welfare payments is relatively small.

1988 Public Welfare and Housing Payments as a Percentage of:

\begin{tabular}{|c|c|c|c|}
\hline Country & $\underline{\text { GNP }}$ & All Government Expenditures & $\begin{array}{l}\text { Per Capita } \\
\text { (1988 US }\end{array}$ \\
\hline Sweden & 22.1 & 54.2 & 19,300 \\
\hline Netherlands & 22.1 & 39.6 & 14,520 \\
\hline UK & 11.6 & 30.9 & 12,810 \\
\hline USA & 7.2 & 31.5 & 19,840 \\
\hline Sri Lanka & 3.7 & 11.7 & 420 \\
\hline Morocco & 2.1 & 7.3 & 830 \\
\hline Korea & 1.3 & 8.5 & 3,600 \\
\hline Thailand & 0.1 & 5.4 & 1,000 \\
\hline Indonesia & 0.04 & 1.7 & 440 \\
\hline Philippines & 0.03 & 2.2 & 630 \\
\hline Uganda & 0.03 & 2.9 & 280 \\
\hline
\end{tabular}

\footnotetext{
${ }^{11}$ These numbers include a wider range of categories than would normally be included in "welfare payments." They cover expenditures on housing and slum clearance activities, sanitary services, compensation payments for sickness and disability, pensions, unemployment payments, family and child allowances, and the cost of providing welfare services such as care for the elderly, the disabled and children. Nonetheless, they are indicative of the relative importance of welfare payments across countries.
} 
Source: World Development Report 1990, "World Development Indicators," Tables 1 and 11, World Bank, Washington, DC 1990.

The main components of the public safety net in the Philippines are food subsidy programs, public works employment, livelihood creation (i.e., training) programs, credit for small and medium enterprises and farms. There is a formal social security program that provides benefits for old-age, disability, death, workman's injury, illness and maternity. But this system only covers government workers and 60 percent of workers in the formal sector.

According to a recent World Bank evaluation, welfare spending in the Philippines is costly to administer and poorly targeted:

Few of the resources currently spent on government livelihood programs or labor-based public works reach the poorest groups. Even the cash and in-kind transfer programs do not target effectively. (p. 49, World Bank [1996]).

The same report also cautioned that "The public provision of a safety net for the poorest must be designed to complement rather than replace existing private arrangements of private transfers, which are already widespread in the Philippines (p. 44)." However, many discussions of private transfer behavior are necessarily impressionistic, because, until recently, information about such transfers was not commonly available in the Philippines.

\section{EMPIRICAL WORK}

\section{A. Descriptive Overview}

The Family Income and Expenditures Survey (FIES) of the Philippines is undertaken every three years to gather income and consumption information for a representative cross-section of Filipino households. The main objective of the survey is to obtain information about expenditure patterns, income sources and inequality and to 
obtain information for updating weights in the consumer price index. The FIES is the only official household survey of income and spending patterns which is nationally representative. ${ }^{12}$

The survey gathers information about sources of income (both cash and in-kind), demographic variables such as family size, marital status and number of children by age group, and job-related information such as earnings and employment status. In addition, the survey asks respondents to report on a variety of transfers, both in-kind and cash, from domestic sources and from overseas. The survey's definition of private transfers includes only interhousehold transfers, so that redistribution within the household is not measured. The FIES covers 18,922 households: 8,863 urban households and 10,059 rural households.

Tables 1 and 2 list household characteristics according to whether households were net recipients or givers of transfers. Table 1 refers to urban households and Table 2 to rural ones. We consider the two separately because of the large differences between urban and rural standards of living.

Nearly all households participate in transfer networks, and private transfers are large component of total household income. Eighty-eight percent of the urban households were involved with transfers, either as donors, recipients, or both. In the urban sample gross transfer receipts accounted for 12 percent of total household income. Among urban recipients, these receipts accounted for nearly 20 percent of total household income.

More households received transfers than gave them, in part because international remittances account for a large fraction of total receipts. Another reason for the discrepancy is that households were asked more questions about receipts than gifts. Only one module in the survey was concerned with gifts and respondents were asked only

\footnotetext{
${ }^{12}$ There is no public use file that is as easily available as similar data sets in the United States. We were able to get a copy of the 1988 FIES as part of a team working on a World Bank basic economic report, and a copies of the data files that we use are available upon request from the authors.
} 
summary questions. Three modules dealt with receipts, including the value of in-kind transfers and those received from abroad. Therefore, gifts are likely to be under-reported relative to receipts. ${ }^{13}$ Despite this, an examination of household characteristics according to their private transfer behavior conveys useful information about private transfer flows. Consider the urban households in Table 1. Recipients have the lowest average pretransfer income (Table 1, column 1), and donors have the highest. This pattern suggests that transfers flow from high- to low-income households. The same pattern exists for rural households (Table 2). Ninety-three percent of them were involved with private transfers and gross transfer receipts made up 12 percent of total income. In both samples, transfer recipients are less educated than donors, and the proportions of female-headed households and households whose head is not employed are higher among recipients than donors.

Private transfers help equalize the distribution of income. In previous work using the data set we found that, for the sample overall, private transfers increase the income share of the lowest quintile by 62 percent, and reduce the share of the top quintile by nearly 6 percent [Cox and Jimenez, 1995]. We also found that private transfers appeared to alleviate poverty, in the sense that poverty rates calculated without including private transfers were much higher than actual ones. ${ }^{14}$ But we did not use a rigorous framework for understanding or estimating non-linearities in the income-transfer relationship.

\section{B. Estimates of Transfer Functions}

How responsive are private transfers to income? To answer this question, we estimate a regression spline model for net transfer receipts, $T$, defined as gross transfers received minus gross transfers given.

1) Specification

\footnotetext{
${ }^{13}$ In the usual case we might suspect under-reporting to work in the opposite direction to the extent that donors exaggerate their generosity or recipients downplay their dependency.

${ }^{14}$ Urban poverty rates were one-third higher without private transfers-- 42 versus 32 percent. The comparable figures for rural households were 66 versus 59 percent (Cox and Jimenez [1995]).
} 
To model nonlinearity, we use a continuous linear spline with a single knot. A continuous linear spline is similar to a threshold regression, with the important exception that the regression function is constrained to be continuous in pre-transfer income $I$. Let $K$ denote the knot, or threshold level of income (as in Figure 1) at which transfer behavior switches from altruistic to non-altruistic. Let $d_{1}(K)$ denote a dummy variable which takes the value 1 if $I \leq K$ and 0 if $I>K$, and let $d_{2}(K)=1-d(k)$ denote a dummy variable which takes the value 1 if $I>K$. For fixed $K$ the continuous linear spline is a linear function of the variables $(I-K) * d_{1}(k)$ and $(I-K) * d_{2}(K)$ as well as the other regressors including an intercept.

If the knot $K$ were known, the model could be estimated by ordinary least squares (OLS). Since $K$ is unknown, it should be estimated along with the other regression parameters. ${ }^{15}$ Non-linear least squares (NLLS) is the appropriate estimation criteria. Since the knot enters in a non-linear and non-differential manner, conventional gradient search techniques to implement NLLS are inappropriate. Instead, we employ a method which is sometimes called conditional least squares, and works as follows. For any $K$ the model is estimated by OLS, yielding the sum of squared errors as a function of $K$. The least squares estimate of $K$ is found by searching over $K$ and selecting the value which yields the lowest sum of squared errors. ${ }^{16}$ For this value of $K$ the slope parameters are estimated by OLS. Chan and Tsay (1998) have shown that these NLLS estimates are consistent and asymptotically normal, and these authors also provide estimates of the asymptotic variance-covariance matrix.

To reduce the influence of the extremely wealthy, we omitted the top $2 \%$ wealthiest households (measured by pre-transfer income) from each sample. Since we

\footnotetext{
${ }^{15}$ In earlier, descriptive work [Cox and Jimenez, 1995] we estimated a spline function for transfer receipts but treated the non-linearity in an ad hoc way by fixing the nodes of the spline at quartiles in pre-transfer income.

${ }^{16}$ For a sample of size $\mathrm{n}$ with $\mathrm{m}$ parameters, at most $\mathrm{n}-2 \mathrm{~m}$ distinct values for $K$ may be considered. For a complete search, it is sufficient to examine the values of $K$ equaling the sample values of the threshold variable (in our case $I$ ), excluding the extremely smallest and largest values to ensure that at least $\mathrm{m}$ observations lie on each side of the threshold. This is what we did for our calculations.
} 
are treating pre-transfer income as exogenous, this does not induce sample selection bias. As a regressor, we included a dummy variable for households with zero pre-transfer income. (The sensitivity of the results to this specification are discussed later.) We also include the level of retirement income and a dummy for the presence of retirement income, to account for the differential behavior of retirees.

We include other household characteristics in addition to pre-transfer income in the transfer function. Education of the household head is included to capture permanent income effects. Age is included because recent evidence indicates that liquidity constraints may play an important role in private transfer behavior (e.g., Cox [1990], Guiso and Jappelli [1991], Cox and Jimenez [1997]). Binding liquidity constraints would affect the timing of transfers. For example, they may be targeted to younger households who have not yet established their reputations in credit markets. We include a dummy variable indicating whether the household is headed by a woman because nearly all studies of private transfers indicate that they are disproportionately targeted toward women (e.g., Lucas and Stark [1985 ,Botswana]; Kaufmann and Lindauer [1986 ,El Salvador]; Cox and Jimenez [1997, Peru]; Guiso and Jappelli [1991, Italy]; Cox [1987, United States]). Further we include a dummy for whether the household head is employed and whether husband and wife are both employed. In addition, we control for marital status, household size and composition.

Female-headed and married households receive much more transfers than others. The gender effect is consistent with the long list of other studies of private transfers that find that transfers are disproportionately targeted toward women. Evidence for marriage effects for transfers is more ambiguous; some studies find positive effects and others negative ones. But part of these demographic effects could be the result of overseas remittances. Consider a household in which the primary earner is the husband. Suppose that he is currently working abroad and remitting part of his income to his wife and children. Since transfers from abroad are much larger than those from domestic sources 
(Table 1), especially large transfers would tend to accrue to married, female-headed households. ${ }^{17}$ We control for this situation by including a dummy for these households. ${ }^{18}$ 2) Estimated Transfer Functions

Transfer function estimates and standard errors ${ }^{19}$ for urban households are given in the first two columns of Table 3. The key parameters are the first three. The estimate of the knot (income threshold) is 20,080 pesos, which corresponds to the 25th sample income quantile. For incomes below the 25th percentile, the slope of the transfer function is -0.37 , implying a high trade-off between income sources. For incomes above the threshold, the estimated transfer function is utterly flat. A good understanding of the transfer function can be found by examining Figure 2, which plots the estimated transfer function (holding all other regressors fixed at their sample means). The non-linear effect of income on transfers is striking and strong, and is consistent with the theory of section II. The point estimates are consistent with the idea, for example, that altruistic transfers are important for low-income households, but are not operative for higher-income groups. ${ }^{20}$ On a final note, households with no pre-transfer income receive an additional 11,586 pesos in transfers above that suggested by the transfer function displayed in Figure 2. This suggests a very strong non-linearity for very low incomes.

It is revealing to contrast the spline with a standard linear specification. If the spline is replaced by a standard linear function, the OLS estimate of the coefficient on income drops to the tiny value -0.014 . Thus a researcher who tests the effect of income

\footnotetext{
${ }^{17}$ Among those urban households who receive a transfer from abroad, the proportion of married female heads is over 3 times higher than in the urban sample overall ( 5 versus 17 percent).

18 This takes into account a major concern that the motives of non-residents who are still considered household members may be different from those of others. What we cannot control for is the possibility that the female may be absent.

19 The reported standard errors are appropriate for homoskedastic errors. Standard errors robust to heteroskedasticity were also calculated, but were not meaningfully different.

${ }^{20}$ The finding of such strong recipient income effects is all the more striking in light of the fact that we cannot include the income of the donor household in the regression. The omission of donor income is likely to bias recipient income coefficients toward zero. Evidence from the United States (Cox and Rank [1992], Altonji, Hayashi and Kotlikoff [1997] and for Peru (Cox and Jimenez [1995]) indicates that such omitted variable bias is indeed positive, though numerically small.
} 
on transfers by fitting a linear model will erroneously conclude that there is no meaningful relationship.

The estimates and standard errors for rural households appear in the third and fourth columns of Table 3, and a plot of the estimated transfer function is given in Figure 3. Rural patterns for transfers are quite similar to urban ones. The most striking similarity is that for income levels below the threshold, the transfer function has the identical slope of -0.37. A slight difference is that for income levels above the threshold, rural households have a slope of -0.03 , which is significantly different than zero. Another difference is that the income threshold (to switch from altruistic to non-altruistic transfers) is 10,576 pesos, which is about one-half that of the urban sample. Since rural incomes are lower, however, the threshold of 10,576 pesos corresponds to the 20th income quantile for the rural sample, which is a point in the income distribution similar to that found for the urban sample.

We assessed the fit of the linear spline through a series of specification tests. First, we replaced the linear spline in income $I$ with an eighth-order polynomial. The estimated transfer functions are displayed in Figures 2 and 3 along with the linear spline estimates. The polynomial functions closely match the shape of the linear spline, giving strong informal support for our chosen specification. (In the following section we discuss formal tests for the spline specification against the polynomial alternative.) Second, we omitted the dummy for households with zero pre-transfer income. For the urban sample, the slope of the transfer function for altruistic transfers (low pre-transfer income) steepened to -0.45 , and that for the rural sample steepened to -0.41 . Third, we allowed the spline function to be quadratic for the non-altruistic (high income) regime, but the quadratic term was statistically insignificant, and the graphs of the estimated transfer functions were not meaningfully different than the graphs for the linear spline presented in Figures 2 and 3. Fourth, we included a quadratic term in the age of the household head, but this variable was insignificant in both samples. 
As a final specification test, we estimated a model which allowed for the kink $K$ to be random across households. Assuming that $K$ is normally distributed with mean $\kappa$ and variance $\omega$ and independent of the regression error, it is straightforward to calculate the conditional mean of $T$ given $I$ and the other regressors. By allowing $\omega>0$, this model softens the kink in the mean transfer function, while $\omega=0$ specializes to the linear spline. We estimated the parameters by NLLS. Our estimates for both the urban and rural samples yielded point estimates for $\omega$ of 0 , which means that the linear spline fits better than the random knot model. We conclude that the data strongly support the linear spline specification.

The threshold has another potentially interesting interpretation as the "private" analog of the Philippine poverty line, which is calculated according to the value of the assumed minimum consumption bundle for an acceptable standard of living. To the extent that the node marks the point that triggers changes in household behavior, it could be interpreted as a poverty line that is perceived by households, either for altruistic reasons or to compensate for lack of access to formal insurance or credit markets. If so, it would be interesting to compare to the Philippine poverty line. In 1988 , the poverty line (adjusted to take into account food requirements for the poor) was computed to be 3,800 pesos per person per year (World Bank [1993]). The income threshold we estimate for urban areas is about 20,080 pesos per household is almost exactly the same, since at 5.3 persons per household, this translates into 3,789 pesos per year.

3) Tests of the Generalized Transfers Model

The generalized theory of private transfers in section II had the strong implication that the transfer function takes the form of a spline, and this motivated the econometric specifications reported in Table 3. Since altruism cum exchange implies the spline form, we can test this hypothesis by testing whether a spline exists in the transfer function.

Testing for the presence of a spline relationship is non-standard from the statistical point of view. The null hypothesis of no spline is equivalent to that the 
regression slopes in the two regimes are equal. But in this case, the knot $K$ is not identified, and it is known that test statistics (such as $t$ - or $F$-statistics) do not have conventional asymptotic distributions. Hansen [1996] shows that the bootstrap allows the calculation of asymptotically valid p-values in this context. Technical details are given in the appendix.

We report bootstrap p-values for the two samples in Table 4. For each model, 1000 bootstrap replications were made. The first line reports Wald statistics and bootstrap p-values of the test of a linear specification against the alternative of a linear spline. In neither sample did a single bootstrap statistic exceed the actual value, yielding estimated p-values of 0.00 , which means that linearity is easily rejected in favor of a linear spline at all significance levels. Similarly, the second line in Table 4 reports tests of a quadratic transfer function (that is, a linear regression of $T$ on $I, I^{2}$, and the other control variables) against the alternative of a quadratic spline (the use of a quadratic spline under the alternative is done so that the hypotheses are nested). Again, the quadratic specification is rejected at all significance levels for both samples in favor of the spline specification. The tests show that the spline is necessary to capture the correct transfer function.

One might ask whether a higher order polynomial could adequately approximate the unknown transfer function. We repeated our hypothesis tests for transfer functions modeled as simple polynomials up to order 7. The results are quite interesting. For the urban samples the spline effect is statistically significant for polynomials of order 5 and below, which is strong evidence that the transfer effect of altruism prevails for lower income households. The evidence from the rural samples is less strong, as the spline effect is marginal in a third order (cubic) polynomial, and insignificant against higherorder polynomials.

Another question is whether the specification of a single knot spline function is appropriate. To assess this question, we performed a two-step Wald test for a second 
knot or threshold effect. Since this testing problem is non-standard, we again used bootstrap methods to assess statistical significance. The results are presented in Table 5 . Neither test statistic is close to significant. This means that with high confidence, the hypothesis of a linear spline with a single knot cannot be rejected against the alternative of a linear spline with two knots.

In summary, the evidence shows that there is strong statistical evidence in favor of a strong kink in the transfer function which is well approximated by a linear spline with a single knot, and cannot be well approximated by a low-order polynomial. This statistical evidence supports the generalized model of altruism described above.

\section{4) Other Results}

Better educated households receive more transfers, which is consistent with altruism in the presence of liquidity constraints [Cox, 1990]. When a recipient faces a binding borrowing constraint, transfers help fill the gap between desired consumption and permanent income. Suppose that the recipient's future income rises, with current income constant. If desired consumption is determined by permanent income, the gap between it and current income widens. Hence the optimal transfer increases. ${ }^{21}$

One instance in which urban and rural samples differ is with respect to estimated age effects. Age-transfer profiles slope downward for urban households but upward for rural ones. While the effect is not pronounced, the sign pattern does suggest that transfers are more likely to function as old-age support in rural areas, where pension coverage is much lower. Negative age effects are also consistent with the idea that private transfers respond to liquidity constraints, since we would expect that transfers would be directed toward consumers who have not yet established reputations in formal credit markets.

\footnotetext{
${ }^{21}$ Consider the following simple numerical example. Suppose that an altruistic donor overlaps with a recipient for two periods. The donor, but not the recipient, has access to capital markets and income of $[200,200]$. The recipient has income of $[60,100]$. Assume that the subjective rate of time preference equals the interest rate and that the donor weights the recipient's utility equal to his own. The consumption profile for each person is $[140,140]$, and first-period transfers are 80. Now suppose that the recipient's second-period income increases by 4 . His optimal consumption is now 141. With current income constant, transfers must rise by 1 to enable the recipient to attain this new level.
} 
The size and composition of the household appears to matter. The presence of infants has no measurable effect on transfers, and young children (up to age 7) have no effect in the rural sample and have a negative effect in the urban sample. Older children (age 8 through 15) have a slight positive effect, and the number of adults has a larger positive effect ( 850 peso per adult for urban, 558 peso for rural).

Households headed by someone who is not employed receive an 8,398 peso boost (urban) in transfers $(5,632$ peso for a rural household). On the other hand, if both the husband and wife both work, then transfer amounts are reduced (1,399 peso for urban, 506 peso for rural). With income constant, dual earner status implies lower earnings per person, which might prompt altruistically motivated transfers. On the other hand, if the husband and wife both work, they may be better able to cope with income variability, which would be consistent with receiving less private transfers.

Finally, we observe that marriage has no effect on transfers, and female-headed households receive a statistically insignificant boost. An important effect is reserved for married female-headed households, which receive increased transfers of 32,131 peso in the urban sample and 15,836 in the rural sample. This is consistent with the hypothesis that the husbands are working abroad and are remitting their income to their spouses.

\section{CONCLUSION}

A primary reason for the surge of interest in family behavior in economics is its implications for government redistribution policy. Researchers and policymakers are both becoming aware that the effects of public income redistribution depend in part on private responses to them, including private transfers. Ironically, it may be that the best place to investigate the effects of the "crowding out" of private transfers for public ones is where little public transfers exist, because in these settings it is likely to be easier to measure the full range of responsive and non-responsive transfers. 
Our results suggest that the potential for crowding out is indeed large for public transfers targeted toward those in the lower reaches of the income distribution. Our spline estimates indicate that, depending on the sample, anywhere from 30 to 80 percent of private transfers could be crowded out for those in (roughly) the lowest quintile of preprivate transfer income.

Our estimated tradeoff between private transfers and recipient income is much higher than existing studies, either for the United States or for developing countries, with one interesting exception that we mentioned earlier. Kaufmann (1982) examined private transfer behavior among urban households in the Philippines and El Salvador. Kaufmann develops a theory of transfers that is different from ours, but is nonetheless focused on a non-linear relationship between transfers and income. ${ }^{22}$ Accordingly, he investigates splined and other non-linear specifications of transfer functions, using small household micro-data sets collected in conjunction with a World Bank project on informal housing. For the Philippines, he finds that "The large and highly significant income coefficient ... indicate(s) that the slope of the function is rather steep--and negative--at low income levels, and that the slope rapidly decreases as income increases." [Kaufmann, p. 172.] Kaufmann's estimated tradeoff between transfers and income for low-income households, -0.625 of a peso, is well within the range of our estimates. And like us, he finds that a simple linear specification performs poorly relative to non-linear ones.

We think this evidence adds to a compelling case paying close attention to nonlinearities in analyzing private transfer behavior. The spline specification implied by the theory necessitates a search for the knot point in the transfer-income relationship. Such searches introduce inference problems, but these can be addressed as shown by Hansen [1996, 1999]. Future work on private transfers should focus on sharp non-linear relationships, preferably in settings where public transfers are small.

\footnotetext{
${ }^{22}$ Kaufmann postulates that private transfers targeted to a household's "basic needs" (e.g., basic food, health and shelter requirements) respond differently than other transfers.
} 


\section{Appendix: The Bootstrap Test for a Spline}

The Wald statistic for testing the hypothesis of a polynomial transfer function against the alternative hypothesis of a polynomial spline function (of the same order) is $W=n\left(S_{0}-S_{1}\right) / S_{1}$, where $S_{0}$ is the sum of squared errors for the polynomial null model (calculated by OLS) and $S_{1}$ is the sum of squared errors for the spline model . To compute the bootstrap p-value, generate a sample of iid random variables drawn from the empirical distribution of the NLLS residuals, and repeat the above procedure, treating the generated data as the dependent variable. Store the resulting Wald statistics, and calculate the percentage which are larger than the actual Wald statistic in the sample. This is the bootstrap p-value.

Since calculation of the spline model involves a large number of regressions, each of which involves nearly 10,000 observations, we restricted the class of possible thresholds to 100 values consisting of equaling spaced quantiles between the 5 th and 95 th quantiles. 


\section{REFERENCES}

Altonji, Joseph G., Hayashi, Fumio and Kotlikoff, Laurence. "Parental Altruism and Inter Vivos Transfers: Theory and Evidence." Journal of Political Economy 105 (December 1997): 1121-1166.

Barro, Robert J. "Are Government Bonds Net Wealth?" Journal of Political Economy 82 (November/December, 1974): 1095-1117.

Becker, Gary S. "A Theory of Social Interactions." Journal of Political Economy 82 (November/December, 1974): 1063-94.

and Murphy, Kevin M. "The Family and the State." Journal of Law and Economics 31 (April 1988a): 1-18.

Chan, K.S. and Ruey S. Tsay. "Limiting Properties of the Least Squares Estimator of a Continuous Threshold Autoregressive Model," Biometrika 45 (1998): 413-426.

Coate, Stephen and Ravallion, Martin. "Reciprocity without Commitment: Characterization and Performance of Informal Insurance Arrangements." Journal of Development Economics 40 (February 1993): 1-24.

Cox, Donald. "Motives for Private Income Transfers." Journal of Political Economy 95 (June 1987): 1045-76.

. "Intergenerational Transfers and Liquidity Constraints." Quarterly Journal of Economics 105 (February 1990): 187-217.

and Rank, Mark. "Inter-Vivos Transfers and Intergenerational Exchange." Review of Economics and Statistics 74 (May 1992): 305-314.

and Jakubson, George. "The Connection Between Public Transfers and Private Interfamily Transfers." Journal of Public Economics 57 (May 1995): 129-167

and Jimenez, Emmanuel. "Private Transfers and the Effectiveness of Public Income Redistribution in the Philippines." In Public Spending and the Poor: Theory and Evidence edited by Dominique van de Walle and Kimberly Nead. Baltimore: The Johns Hopkins University Press (for The World Bank), 1995.

, Eser, Zekeriya, and Jimenez, Emmanuel. "Motives for Private Income Transfers Over the Life-Cycle: An Analytical Framework and Evidence for Peru." Journal of Development Economics 55 (February 1998): 57-80.

Cutler, David M. and Gruber, Jonathan. "Does Public Insurance Crowd Out Private Insurance?" Quarterly Journal of Economics 111 (May 1996): 391-430.

Dunn, Thomas. "The Distribution of Intergenerational Income Transfers Across and Within Families." Mimeographed. Syracuse, NY: Syracuse University, 1994. 
Feldstein, Martin. "Social Security, Induced Retirement, and Aggregate Capital Accumulation." Journal of Political Economy 82 (October, 1974): 905-926.

Gale, William and Scholz, John Karl. "Intergenerational Transfers and the Accumulation of Wealth." Journal of Economic Perspectives 8 (Fall 1994): 145-160.

Guiso, Luigi and Tullio Jappelli. "Intergenerational Transfers and Capital Market Imperfections: Evidence from a Cross-Section of Italian Households." European Economic Review 35 (January 1991): 103-120.

Hansen, Bruce E. "Inference When a Nuisance Parameter is Not Identified Under the Null Hypothesis." Econometrica 64 (March 1996): 413-430.

Hansen, Bruce E. "Sample Splitting and Threshold Estimation." Econometrica 67 (1999): forthcoming.

Ioannides, Yannis M. and Kan, Kamhon. “The Nature of Two-Directional Intergenerational Transfers of Money and Time: An Empirical Analysis." Manuscript. Blacksburg: Virginia Polytechnic Institute and State University, March 1993.

Kaufmann, Daniel. "Social Interaction as a Strategy for Survival Among the Urban Poor: A Theory and Evidence." Ph.D. Dissertation, Harvard University, 1982. and David Lindauer. "A Model of Income Transfers for the Urban Poor." Journal of Development Economics 22 (July/August 1986): 337-50.

Laitner, John. "Intergenerational and Interhousehold Economic Links." in Mark R. Rosenzweig and Oded Stark, eds., Handbook of Population and Family Economics. Amsterdam: North-Holland, 1997.

Lopez, Maria Elena. "The Filipino Family as Home for the Aged." Research Report No. 91-7, Population Studies Center, University of Michigan, January, 1991.

Lucas, Robert E. B. and Oded Stark. "Motivations to Remit: Evidence from Botswana." Journal of Political Economy 93 (October 1985): 901-18.

Mace, Barbara. "Full Insurance in the Presence of Aggregate Uncertainty." Journal of Political Economy 99 (October 1991): 928-956.

McElroy, Marjorie B. "The Empirical Content of Nash-Bargained Behavior." Journal of Human Resources 25 (Fall 1990): 559-83.

McGarry, Kathleen and Schoeni, Robert F. "Transfer Behavior in the Health and Retirement Study: Measurement and the Redistribution of Resources Within the Family." Journal of Human Resources 30 (Supplement 1995): S184-S226. 
Menchik, Paul L. "Primogeniture, Equal Sharing and the U.S. Distribution of Wealth." Quarterly Journal of Economics 94 (March 1980): 299-316.

Moffitt, Robert. "Incentive Effects of the U.S. Welfare System: A Review." Journal of Economic Literature 30 (March 1992): 1-61.

Ravallion, Martin and Lorraine Dearden. "Social Security in a 'Moral'Economy: An Empirical Analysis for Java." Review of Economics and Statistics 70 (February 1988): 36-44.

Roberts, Russell D. "A Positive Model of Private Charity and Public Transfers." Journal of Political Economy 92 (June 1984): 136-148.

Schoeni, Robert F. "Private Interhousehold Transfers of Money and Time: New Empirical Evidence." Review of Income and Wealth 43 (December 1997): 423-448.

Townsend, Robert M. "Risk and Insurance in Village India." Econometrica 62 (May 1994): 539-591.

Wilhelm, Mark O. "Bequest Behavior and the Effect of Heirs' Earnings: Testing the Altruistic Model of Bequests." American Economic Review 86 (September 1996): 874-92.

The World Bank. World Development Report. New York: Oxford University Press, 1990. . The Philippines: An Opening for Sustained Growth. Report no. 11061-PH. Washington, DC, processed, 1993.

A Strategy to Fight Poverty. Washington, DC: The World Bank, 1996. 
Table 1

Selected Characteristics of Filipino Urban Households by Private-Transfer Status

$\underline{\text { Variable }}$

Income

Total income before transfers

Proportion with retirement income

Retirement income

Total income after transfers

\section{Education}

Some primary or none

Primary graduate

Some secondary

Secondary graduate

Some university

University graduate

Other Characteristics

Age of household head

Married

Female-headed households

Husband and wife both work

Head not employed

No. of children aged 1 or less

No. of children aged 1 to 7

No. of children aged 8 to 15

Household size

Transfers

Proportion giving net transfers

Net transfers given (amount)

Proportion receiving net transfers

Net transfers received (amount)

Proportion giving gross transfers

Gross transfers given (amount)

Proportion receiving gross transfers

Gross transfers received (amount)

Proportion receiving from abroad

Transfers received from abroad (amount) 6,518.75

Number of cases
(1)

$\begin{array}{cc}\text { Net Transfer } & \text { Net Transfer } \\ \text { Recipients } & \underline{\text { Donors }}\end{array}$

6,801

(3)

(4)

All

$\begin{array}{crrr}46,730.30 & 123,720.50 & 81,937.29 & 59,522.50 \\ 0.063 & 0.078 & 0.066 & 0.065 \\ 862.429 & 2,225.170 & 1,014.570 & 1,031.140 \\ 56,796.54 & 122,460.44 & 81,937.29 & 67,246.81\end{array}$

0.175

0.200

0.137

0.138

0.166

0.125

0.144

0.180

0.117

0.227

0.203

0.141

0.133

0.163

0.268

0.174

0.191

0.123

0.219

0.143

0.158

45.376
0.824
0.185
0.291
0.183
0.115
0.789
1.071
5.270

47.072

44.715

0.861

0.114

0.312

0.132

0.103

0.763

1.003

5.390

45.482

0.830

0.170

0.304

0.169

0.111

0.771

1.057

5.425

0.000
0.000

1.000

$10,066.24$

0.429

194.22

1.000

$10,260.46$

0.264

1.000
$1,260.060$
0.000
0.000
1.000
$1,511.57$
0.451
251.514
0.005
25.000

0.000

0.000

0.000

0.000

0.008

2.891

0.008

2.891

0.000

0.000

976

1,086

a. Neither a net-transfer recipient nor a net-transfer donor. 
Table 2

Selected Characteristics of Filipino Rural Households by Private-Transfer Status

(1)

$\begin{array}{cc}\begin{array}{c}\text { Net Transfer } \\ \text { Recipients }\end{array} & \text { Net Transfer } \\ & \underline{\text { Donors }}\end{array}$

$\underline{\text { Variable }}$

Income

Total income before transfers

Proportion with retirement income

Retirement income

Total income after transfers

\section{Education}

Some primary or none

Primary graduate

Some secondary

Secondary graduate

Some university

University graduate

Other Characteristics

Age of household head

Married

Female-headed households

Husband and wife both work

Head not employed

No. of children aged 1 or less

No. of children aged 1 to 7

No. of children aged 8 to 15

Household size

Transfers

Proportion giving net transfers

Net transfers given (amount)

Proportion receiving net transfers

Net transfers received (amount)

Proportion giving gross transfers

Gross transfers given (amount)

Proportion receiving gross transfers

Gross transfers received (amount)

Proportion receiving from abroad

Transfers received from abroad (amount) 1,835.43

Number of cases
8,332

$\begin{array}{rrrr}22,899.29 & 41,539.12 & 26,792.76 & 25,098.24 \\ 0.023 & 0.021 & 0.013 & 0.022 \\ 220.539 & 249.757 & 141.505 & 218.205 \\ 26,711.54 & 40,749.30 & 26,792.76 & 28,255.98\end{array}$

$25,098.24$

0.438

0.424

0.230

0.109

0.094

0.107

0.106

0.058

0.426

0.436

0.253

0.107

0.269

0.130

0.032

0.096

0.036

0.071

0.051

0.108

0.050

0.041

$\begin{array}{rrrr}46.402 & 45.119 & 45.218 & 46.188 \\ 0.849 & 0.907 & 0.862 & 0.856 \\ 0.123 & 0.066 & 0.102 & 0.116 \\ 0.271 & 0.270 & 0.259 & 0.271 \\ 0.094 & 0.040 & 0.063 & 0.086 \\ 0.129 & 0.102 & 0.108 & 0.125 \\ 0.896 & 0.850 & 0.862 & 0.889 \\ 1.249 & 1.237 & 1.192 & 1.244 \\ 5.290 & 5.390 & 5.211 & 5.295\end{array}$

\subsection{0 \\ 0.000}

1.000

$3,812.25$

0.473

115.663

1.000

3,927.92

0.126

1.000
789.823
0
0
1.000
$1,023.99$
0.611
234.165
0.009
8.075

1,044

683

$\begin{array}{lr}0.000 & 0.104 \\ 0.000 & 81.974 \\ 0.000 & 0.828 \\ 0.000 & 3,157.74 \\ 0.013 & 0.497 \\ 2.792 & 202.272 \\ 0.013 & 0.893 \\ 2.792 & 3,278.04 \\ 0.000 & 0.105 \\ 0.000 & 1,521.15\end{array}$

10,059

a. Neither a net-transfer recipient nor a net-transfer donor. 
Table 3

Transfer Functions

Dependent Variable---Net Transfers Received ${ }^{\mathrm{a}}$

(1)

(2)

Urban Households Rural Households

$\underline{\text { Variable }}$

Income

Income Threshold (K)

Income below $\mathrm{K}$

Income above $\mathrm{K}$

No Income

Retirement income

Has retirement income

\section{Education}

Primary graduate

Some secondary

Secondary graduate

Some university

University graduate

Other Characteristics

Age of household head

Female-headed households

Married

Married and Female-headed

No. of children aged 1 or less

No. of children aged 1 to 7

No. of children aged 8 to 15

No. of adults

Husband and wife both work

Head not employed

Constant

\section{Coefficient}

$\underline{\text { Standard Erro }}$

$\begin{array}{cccc}20,080 & (1967) & 10,576 & (995) \\ -0.373 & (0.075) & -0.372 & (0.074) \\ -0.002 & (0.006) & -0.028 & (0.007) \\ 11,586 & (2899) & 14,066 & (4686) \\ -0.039 & (0.025) & -0.109 & (0.056) \\ -1,225 & (896) & 933 & (788)\end{array}$

$\begin{array}{rlll}1175 & (634) & 1,168 & (204) \\ 697 & (717) & 1,352 & (296) \\ 3873 & (645) & 2,502 & (292) \\ 6425 & (723) & 4,415 & (404) \\ 6901 & (754) & 5,022 & (494)\end{array}$

$\begin{array}{rrrr}-32 & (18) & 18.0 & (7.7) \\ 1,265 & (1005) & 689 & (449) \\ 322 & (910) & 372 & (395) \\ 32,131 & (1364) & 15,836 & (733) \\ -66 & (577) & -43 & (240) \\ -384 & (210) & -43 & (91) \\ 377 & (160) & 226 & (65) \\ 850 & (129) & 558 & (68) \\ -1,399 & (443) & -506 & (194) \\ 8,398 & (595) & 5,632 & (333) \\ -835 & (1369) & -1,815 & (581)\end{array}$

Observations

8,684

9,857

0.24

0.17

a. Dependent variable is gross transfers received minus gross transfers given. 
Table 4

Bootstrap Tests of Polynomial Transfer Function Against Spline Transfer Function

Polynomial

Order

$\underline{\text { Urban }}$

$\underline{\text { Rural }}$

\begin{tabular}{|c|c|c|c|c|}
\hline & $\underline{\text { Wald Statistic }}$ & ${\underline{\mathrm{P}-V_{\text {Value }}}}^{\mathrm{a}}$ & $\underline{\text { Wald Statistic }}$ & $\underline{\mathrm{P}}-$ Value $^{\mathrm{a}}$ \\
\hline 1 & 49.8 & 0.00 & 41.4 & 0.00 \\
\hline 2 & 38.2 & 0.00 & 23.7 & 0.00 \\
\hline 3 & 28.9 & 0.00 & 14.7 & 0.04 \\
\hline 4 & 20.0 & 0.02 & 10.3 & 0.27 \\
\hline 5 & 21.0 & 0.03 & 10.0 & 0.42 \\
\hline 6 & 15.3 & 0.20 & 11.0 & 0.45 \\
\hline 7 & 14.3 & 0.35 & 13.4 & 0.32 \\
\hline
\end{tabular}

Table 5

Bootstrap Tests of Single Knot Spline

Against Double Knot Spline

Urban

Wald Statistic

0.37
$\underline{\mathrm{P}-V a l u e}^{\mathrm{a}}$

0.97
Rural

$\underline{\text { Wald Statistic }} \underline{\text { P-Value }}^{\mathrm{a}}$

2.53

0.45

a. Percentage of simulated Wald statistics which exceed sample Wald statistic out of 1000 bootstrap replications. Pvalues less than 0.05 indicate rejection at the $5 \%$ level. 
Figure 1.

The Relationship Between Private Transfers and Income

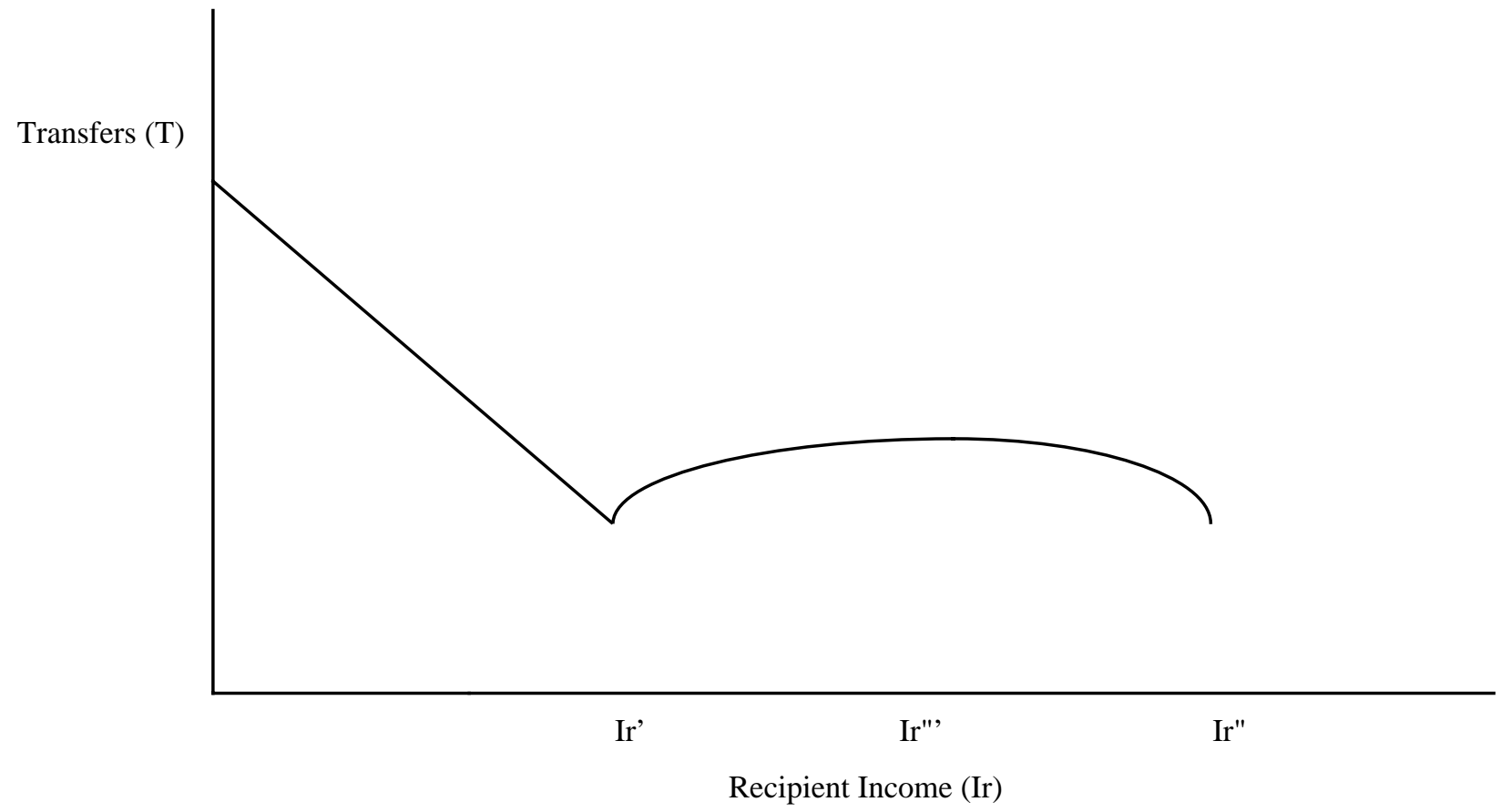


Figure 2

Transfer Functions for Urban Households

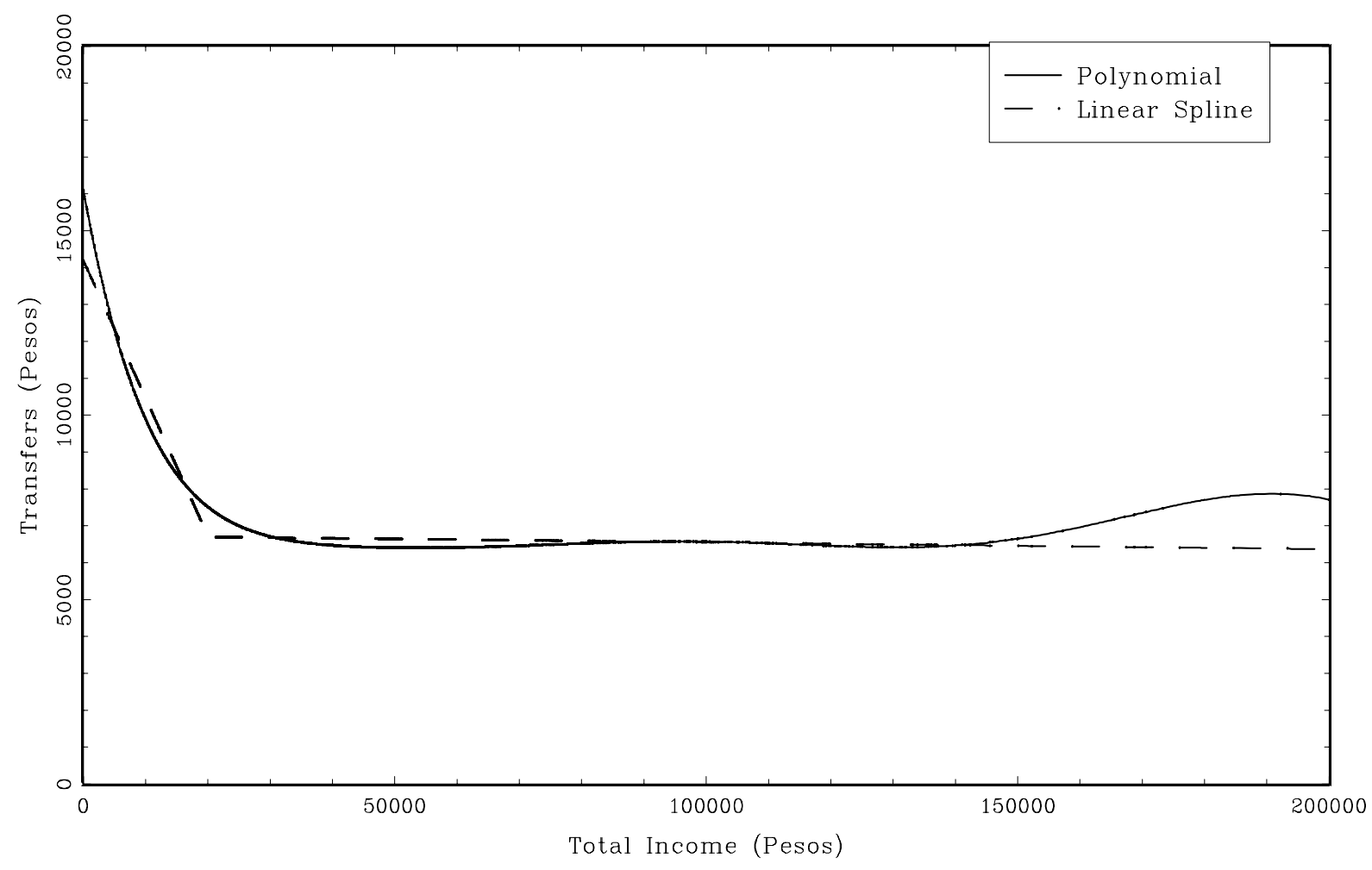

Figure 3

Transfer Functions for Rural Households

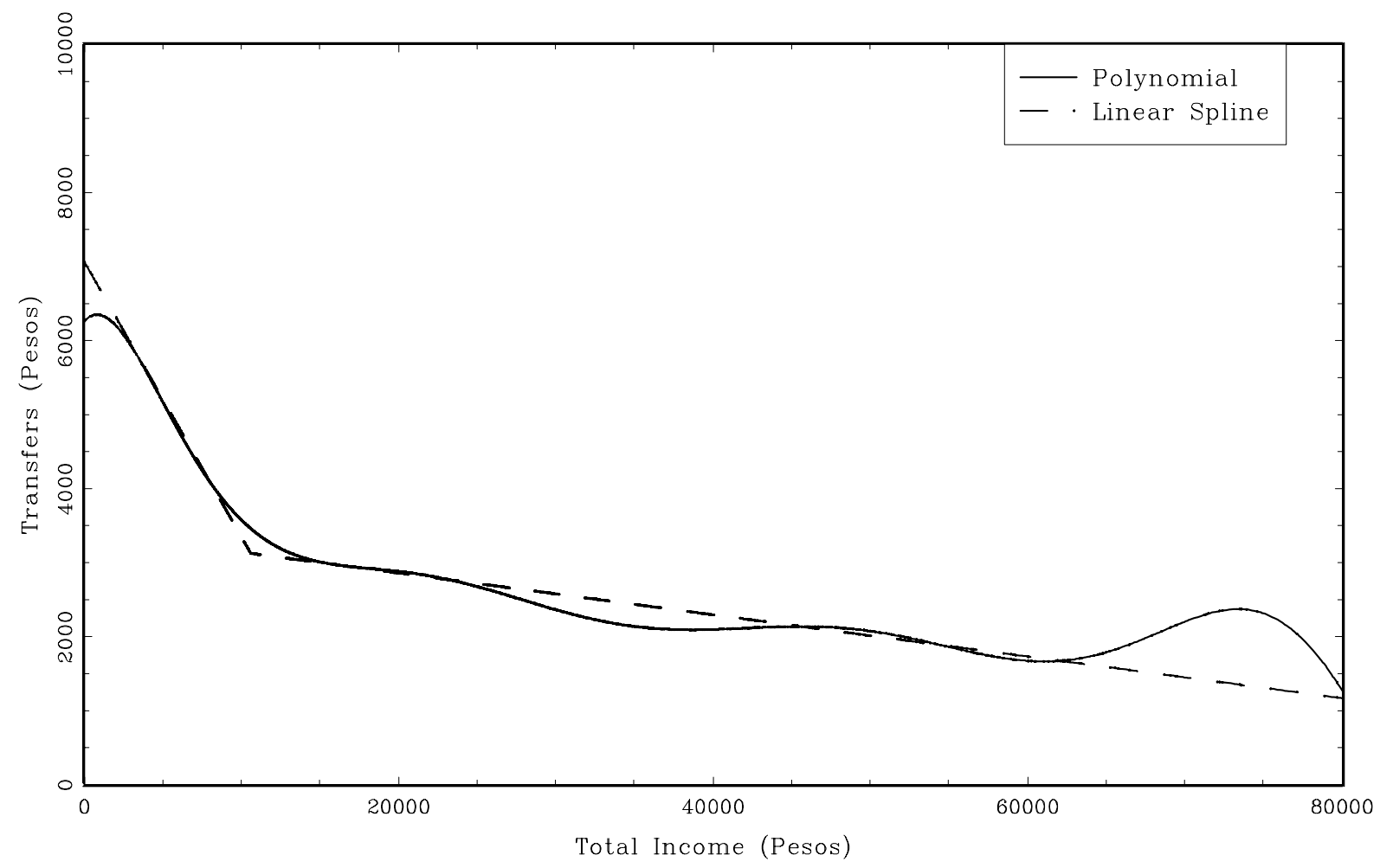

